\title{
Psychological changes arising from an Antarctic stay: Systematic overview
}

\section{Alterações psicológicas decorrentes da permanência na Antártica: revisão sistemática}

\author{
Marilene ZIMMER $^{1,2}$ \\ João Carlos Centurion Rodrigues CABRAL ${ }^{1}$ \\ Fernanda Czarneski BORGES ${ }^{1}$ \\ Karen Gonçalves CÔCO \\ Bianca da Rocha HAMEISTER'
}

\begin{abstract}
Long-term stays in extreme environments, such as Polar Regions, may cause significant changes in the health and well-being of individuals. A systematic overview aimed to map studies about the psychological effects on Antarctic expeditioners. The reviewed data were categorized and divided into two thematic axes: Negative Effects, resulting from harmful psychophysiological variations caused by exposure to the polar stressors, which may present seasonal symptom patterns, altering cognitive performance, mood and interpersonal relationships; and Positive Effects, such as salutogenic results arising from successful adaption to environmental adversities. Due to the great deal of evidence, it is suggested that protection factors should be promoted through preventive approaches, such as psychological training and support in order to reduce symptoms and generate satisfactory adaptation to Antarctica.
\end{abstract}

Uniterms: Antarctic regions; Environmental psychology; Social isolation; Stress.

\section{Resumo}

A permanência em ambientes de condições extremas, como regiões polares, pode provocar alterações significativas na saúde e no bem-estar dos indivíduos. Por meio de uma revisão sistemática, objetivou-se mapear pesquisas sobre efeitos psicológicos em expedicionários antárticos. Os dados revisados foram categorizados e divididos em dois eixos temáticos: Efeitos Negativos, que resultam de variações psicofisiológicas nocivas causadas pela exposição aos estressores polares, podendo apresentar padrões sazonais nos sintomas, alterando o funcionamento cognitivo, estado de humor e relações interpessoais; e Efeitos Positivos, resultados salutogênicos, decorrentes da adaptação bem sucedida às adversidades ambientais. Devido ao número de evidências, sugere-se que fatores de proteção sejam promovidos por abordagens preventivas, como treinamento e suporte psicológico, a fim de reduzir sintomas e gerar uma adaptação satisfatória à Antártica.

Unitermos: Antártica; Psicologia ambiental; Isolamento social; Estresse.

$\boldsymbol{\nabla} \boldsymbol{\nabla} \boldsymbol{\nabla}$

1 Universidade Federal do Rio Grande, Curso de Psicologia. Av. Itália, km 8, s/n., Campus Carreiros, 96201-000, Rio Grande, RS, Brasil. Correspondência para/Correspondence to: M. ZIMMER.E-mail: <marilenezimmer@furg.br>.

2 Universidade Federal do Rio Grande, Grupo de Pesquisa Psicologia em Condições Extremas. Rio Grande, RS, Brasil. 
Human beings are highly resistant and adaptable to the most varied environmental conditions. However, to live and to work in an extreme-condition environment is a constant challenge to the health and well-being of individuals (Mullin, 1960). Very little is known about the real psychological demands on people exposed to physical and social harshness in unusual environments, such as on submarines, space stations and polar expeditions (Suedfeld, 1998). Such places share specific characteristics, such as narrow spaces, exposure to dangerous situations, social isolation, limitations in communication with the outside world, a high workload, and limited possibilities of evacuation from the environment (Lugg \& Shapanek, 1999; Tafforin, 2002; Wood, Lugg, Hysong \& Harm, 1999). Furthermore, physical factors might act as psychological stressors and thus diminish individual performance, interfere with team performance, and/or compromise the mission's successful achievement, as well as increase crew health and safety risks. To understand such demands is of major importance for mission planning. However, there are few places that allow the investigation of psychological adaptation to extreme environmental conditions.

Geographically remote, Antarctica is the coldest, windiest, and driest area with the highest average altitude on the planet, where photoperiods last as long as six months per year. In addition, it is the area of the planet which is the best preserved and the most prone to global alterations (Bradbury, 2002; Daher \& Brito, 2007; John Paul, Mandal, Ramachandran \& Panwar, 2010). These characteristics make this continent, dedicated to science and peace (Souza, 2008), a unique natural laboratory for research on the psychosocial adaptation of human beings to extremely severe circumstances. Ever since the first voyages into the interior of the Antarctic Continent, concerns with the success of the mission and the health risks due to the inherent challenges of the environment were constant in the planning and performing of expeditions (Law, 1960; Mullin, 1960; Noakes, 2006). Nonetheless, systemic studies directed toward understanding and promoting a satisfactory behavioral response were only outlined slightly before the beginning of the 1960s (Palinkas \& Suedfeld, 2008). Research on the psychological and psychiatric aspects are being performed in many polar 416 programs sponsored by those countries which participate in the Antarctic Treaty. However, psychosocial deprivation and the role of physical factors still represent significant challenges to human resilience.

The majority of these studies concentrate on the harmful and pathogenic effects resulting from behavioral and psychophysiological alterations arising from exposure to environmental stressors and long periods of isolation and confinement (Steel, 2005). Depressive symptomatology, sleep disturbances, cognitive impairment, irritability and interpersonal conflicts, social withdrawal, and fatigue have been frequently reported since the first studies were performed in Polar Regions (Mullin, 1960; Nelson, 1963; Palmai, 1963). These studies also dealt with the identification of risk factors, such as personality traits and sociodemographic characteristics (Law, 1960). The etiologies of symptoms are usually associated with stress and physical exhaustion, lack of environmental stimuli,circadian rhythmalteration, personal disagreements, and hormone levels related to the cold (Palinkas, 1992; Palinkas \& Suedfeld, 2008; Wood et al., 1999). Some researchers identified seasonal patterns of symptoms and began referring to them as Winter-over Syndrome, Polar T3 Syndrome, and Subsyndromal Seasonal Affective Disorder, and these patterns have been used to measure the adaptation to austral winter (Palinkas, 1991; Palinkas, Houseal \& Rosenthal, 1996; Reed et al., 2001). Despite research on the symptoms and their relationships with environmental condition adjustment variations, a scientific consensus is still far from being reached. Furthermore, it is known that these symptoms only reach clinical intervention significance in a low percentage of cases (Palinkas, Cravalho \& Browner, 1995).

There is an emerging theme in polar research, highlighting the salutogenic and positive effects of such experiences (Palinkas, 1986; Steel, 2005). These studies emphasize the strategies used to cope with the adversities of staying in a place with severe conditions and the capacity to overcome the typical daily stressors of polar expeditions. Personal traits are often seen as a decisive protective factor for a healthy stay in inhospitable locations (Palinkas \& Suedfeld, 2008; Wood et al., 1999). Currently this concept is increasingly altering the performance and design of research carried out in this environment. 
The understanding of these effects is of high importance for mission planning, as well as the prevention and promotion of factors related to successful psychosocial adaptation. Challenges can have a positive or negative impact both on the professional performance of the crew and their personal health. Thus, an increasing number of studies have focused on the need to improve prior screening and training in order for teams to successfully accomplish the mission and ensure salutogenic results for the expedition members (Tafforin, 2002; Bishop, 2004).

Considering the diversity of the factors that influence the psychophysiological responses at high latitudes, the need for the construction of this, so far non-existent, consensus on some variables should be emphasized. Thus, this should be supported by the review of studies and the description of scientific data used as tools employed in theoretical development that indicate trends based on consistent evidence. This more comprehensive approach provides a systemic view of the factors related to environmental behavior, and is therefore essential for the consolidation of the field of knowledge throughout Latin America.

Given this context, this review intends to identify, analyze, synthesize, and categorize data on the psychological and health effects in Antarctic expedition team members from the scientific literature published during 2000s.

\section{Method}

The search for publications was performed in eight databases: Scopus; PubMed (MedLine); Clase; IndexPsi Periódicos Técnico-Científicos; Pepsic; ScieLO Brasil; and Lilacs, considering the period between January 2000 and August 2010. The search was conducted with the following keywords, "Psychology", "Psychological", "Psychiatry", "Psychiatric", "Cognitive", "Medicine", "Adaptation + Human", "Behavior + Human", "Stress + Human"and "Coping + Human"in combination with search descriptors, "Antarctic","Antarctica,"'Isolated Environment", "Polar + Environment", "Polar + Regions", "Polar + Station", "Cold + Long Term" and "Extreme + Environment". In the Latin American databases the same search descriptors were employed with the corresponding Spanish and Portuguese keywords. In addition, reference citations from identified publications were reviewed when considered relevant.

The following inclusion criteria were adopted for the study selection: studies about Antarctic expeditions; article published between January 2000 and August 2010, written in the languages, Portuguese, Spanish, or English. Exclusion criteria were: studies that did not present, directly or indirectly, data referring to psychological aspects; papers written in other languages than the aforementioned; and articles unavailable for free online consultation.

Thus 65 publications were identified and from these, 8 were excluded for not being scientific papers; one for not being written in the aforementioned languages; 12 for not being available in free on-line format; as a result, 44 publications were reviewed.

The reviewed papers were sorted by author, year of publication, aims, type of study, and results achieved. Afterwards, they were further grouped by similarity of findings into two thematic axes (Negative Effects and Positive Effects) and then organized according to categories. The category choices were set up from a consensus reached by the authors of the present paper. Data was analyzed into absolute and relative frequencies using the Statistical Package for the Social Sciences (SPSS) version 19.0 software.

\section{Results}

The revised data were categorized into two thematic axes: Negative Effects and Positive Effects (Figure 1). However, a general overview of the papers on Antarctic psychological effects is presented first. The types of study design were Observational Research (18 studies); Literature Review (17 studies); and Experimental Research (7 studies) while in the latter group only four were randomized studies. Among the 44 publications, $81 \%$ were quantitative studies, and the data collection was performed mainly in Winter (10), Summer (4), or in both seasons (11). However, even in the studies performed in both seasons, there was a clear preferential focus on data generated during the course of the winter, precisely because it is a more extreme season in both physical (cold and absence of solar light) and psychological (intense isolation and confinement) 
terms. Among the eleven countries thus identified as performing studies on Antarctic expeditions, the United States (10 studies), France (6 studies), Australia (4 studies), Italy (3 studies), England (3 studies), and India (2 studies) can be highlighted, as well as three other studies carried out by multinational teams. The analogy with space travel was rather recurrent throughout the studies (30 mentions).

\section{Negative effects}

Every reviewed study considered the possibility of negative psychological effects on expeditioners. These effects range from interferences in their general psychological health to higher psychiatric disturbances, going through environmental maladaptive difficulties and symptoms generated by the individual physical and social characteristics. Some of these effects can also compromise the working performance of the team and 79.5\% of the papers mentioned the polar environment as a possible disrupter of individual or team performance.

Psychological health can be significantly affected. Mood and cognition alteration problems are still reported on polar expeditions, even after significant investments in the research station structure. The often frequent symptoms reported by scientists in their publications were cognitive impairment (63.6\%), depression and low moods (56.8\%), anxiety (47.7\%), and irritability (45.4\%) both in the empirical research and the literature reviews. Diverse etiologies for the alterations in cognitive performance were proposed, such as effects of hormone alterations (13.6\%), stress and fatigue (9.0\%), maladaptive difficulties (6.8\%), as well as individual characteristics (4.5\%), the presence of syndromes (4.5\%), low environmental stimulation (4.5\%) and exposure to cold (4.5\%). Some of these studies considered the possibility of multiple influences on cognitive alterations (John Paul et al., 2010). Many publications (43.1\%) refer to the difficulty in adapting

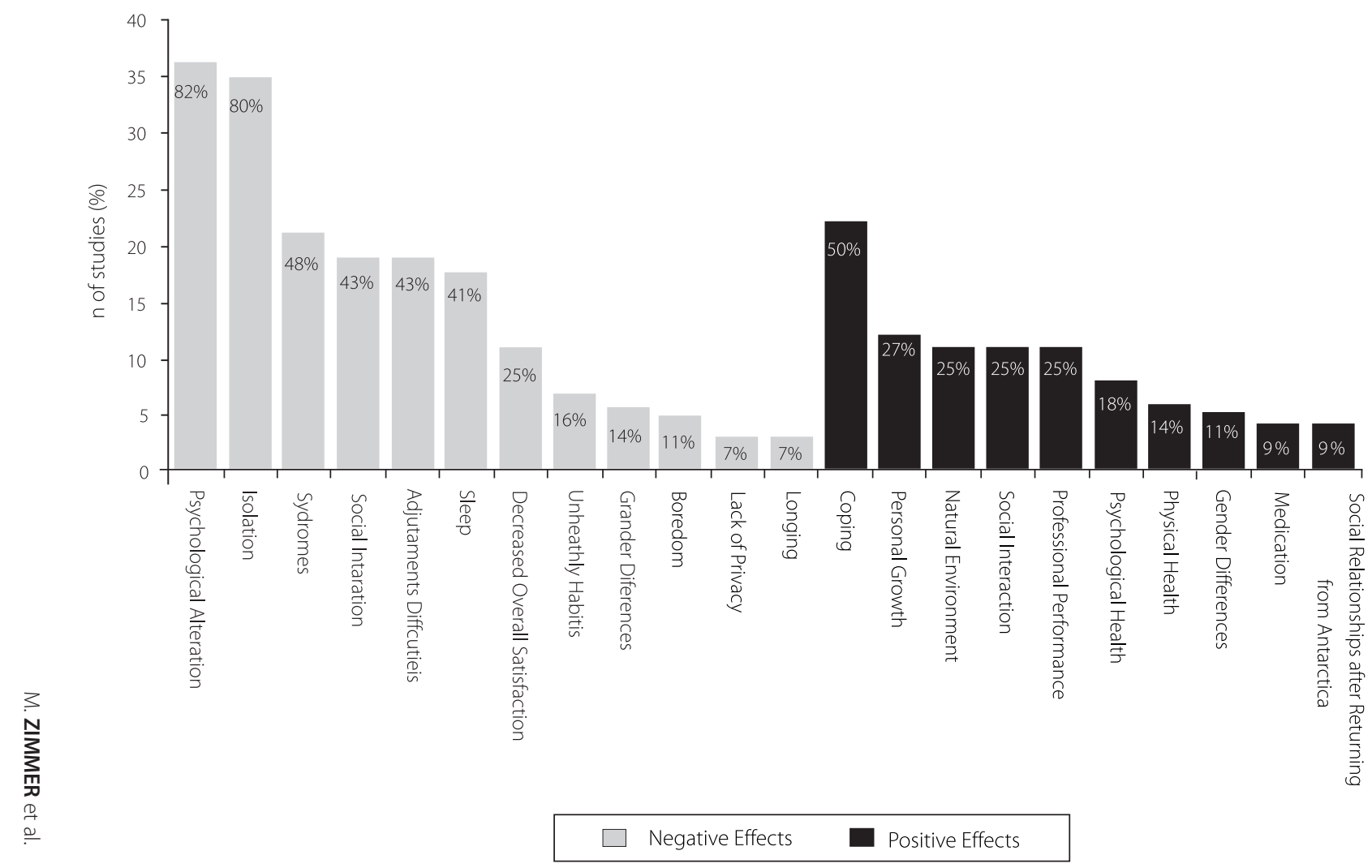

Figure 1. A comparison of data from publications (2000 - 2010) regarding the categories of negative effects and positive effects of living in 418 Antarctica. 
to Antarctic stressors, where this lack of adjustment can generate sleep pattern alterations in the crewmembers. Sleep disturbances were cited in $40.9 \%$ of the studies, with the recurring alterations mentioned being trouble falling asleep, difficulties staying asleep and outright insomnia, with slow-wave and REM sleep reductions also cited. These sleep alterations mostly occurred in midwinter (Palinkas \& Suedfeld, 2008). Isolated and confined environments are mentioned in $84.0 \%$ of the publications as one of the most significant stressors during an Antarctica stay, mainly in long periods during the austral winter. Climactic severity, photoperiods, confinement, and social/physical isolation can become challenges to the human adaptation capacity (Décamps \& Rosnet, 2005; Sandal, Léon \& Palinkas, 2006).

Difficulties in adapting to the polar environment may exhibit a seasonal pattern of symptoms (Palinkas et al., 2001; Palinkas, 2003). Many studies focused on the quantification of syndrome patters related to residing in Antarctica, being mentioned in $47.7 \%$ of the studies reviewed. The patterns of symptoms that were most often reported included Winter-over Syndrome (31.8\%), Polar T3 Syndrome (20.4\%), and the Seasonal Affective Disorder-SAD (13.6\%). However, only 5.0\% of the individuals met the Diagnostic and Statistical Manual of Mental Disorders - Fourth Edition (DSM-IV) or International Statical Classification (CID-10, Classificação Internacional de Doenças) criteria for a more severe psychiatric disorder (Lugg, 2005; Palinkas, Glogower, Dembert, Hansen \& Smullen, 2004a). It is relevant to note that prior to most Antarctic programs the expeditioners were submitted to medical and psychological screening before being accepted into the team, with each individual with a history of psychiatric disorders or otherwise considered unsuitable for the expedition being removed from the field mission.

To understand the psychosocial stressors is also a significant goal present in these studies. Many papers (43.1\%) mention interpersonal conflicts and of those, three cite the lack of privacy as a source of interpersonal tension. The longing for family and friends is also considered as a source of stress in $6.8 \%$ of the reviewed papers. In addition, gender differences within a work group can make individual adaptation more difficult (Sandal et al., 2006). Three studies reported that heterogeneity may be a risk factor for the women in the group and the concern for the welfare of other members of the group the main cause of this distress. On the other hand, gender homogeneity is reported as detrimental in all-male groups (9.0\%), mainly due to greater competitiveness, hostility, and interpersonal tension.

A decreased sense of general satisfaction was reported in $25 \%$ of the publications, particularly in relation to satisfaction obtained from the work, diminished productivity, low morale, and decreased well-being and optimism.

\section{Positive effects}

Salutogenic results due to overcoming stressors can prevail in expedition members (Suedfeld \& Steel, 2000; Suedfeld \& Weiss, 2000). Evidence indicates a trend in the study of positive effects, which were reported in $65.9 \%$ of the publications. These effects vary from individual characteristics to social and professional support as promoters of psychological health. Improved emotion and mood, and a decline in factors related to psychological functioning disturbances were quoted in $18.1 \%$ of the papers. Some studies (27.2\%) also considered the possibility of a linear adaptation by stages. However, the psychological adaptation explanatory mechanisms most mentioned were those related to successful coping strategies, a factor mentioned in $52.2 \%$ of those publications.

Psychosocial characteristics present in the expedition framework may also play a role as protection factors toward the well-being of polar expedition members (Palinkas, Johnson \& Boster, 2004b; Rosnet, Jurion, Cazes \& Bachelard, 2004). Some evidence suggests that cultural and gender heterogeneity within the group may become facilitators for psychological adjustment (15.9\%), improving task performance, increasing motivation and providing healthier interpersonal conviviality. Two studies found that women in mixed groups perform the roles of cohesion promoters within the team. All-female polar groups present good focus on the working tasks, high communication between members, high motivational levels, and low competitiveness (6.8\%). Some of the reviewed studies (25.0\%) reported that well-conducted leadership over the polar group facilitates group cohesion, working team performance and also decreases stress and 
tension among individuals. An efficient group leader must present characteristics such as the clear communication of roles and responsibilities, and sensitivity to the problems and well-being of the team, as well as a perception that the leader's role should provide a model for the other team members (Sandal et al., 2006; Schmidt, Wood \& Lugg, 2005).

Personal growth and a satisfactory professional performance within the Antarctic environment are generally related to individual characteristics. These traits are associated with social compatibility, skill in performing tasks, and emotional stability (Palinkas, 2003; Rosnet, Le Scanff \& Sagal, 2000). The most mentioned individual traits that are predictors of good performance and successful adaptation were high motivational level (22.7\%), low need for social support (13.6\%), low levels of extroversion (13.6\%), low levels of neuroticism (9.0\%), low assertiveness level (9.0\%), low need for interpersonal interaction (6.8\%), and the capacity to deal well with reduced environmental stimuli (6.8\%). Other factors also mentioned included tolerance to boredom, openness to new experiences, and shared problem solving and decision making. In addition, there was a consensus that people with a history of psychiatric disorder should be considered unsuitable.

The proportion of studies with data on adverse effects is significantly higher than those that cover positive effects. Thus, the majority of the papers (70.4\%) cite the processes of psychological selection, training and/or support as decisive aspects for environmental adaptation, individual performance, and team functioning. Prevention of psychological effects is an important factor in the planning of missions (15.9\%). However, psychological assessment instruments used with Antarctic teams still need validation and cross-cultural adaptation (Bishop, 2004) for these highly motivated scientific and military populations coming from a number of different countries. Among the 38 psychological assessment instruments employed in the studies, eight were specifically developed for the study itself, however, the most used instruments were Profile of Mood States (POMS) (6), Positive and Negative Affect Schedule (PANAS) (3), Neo Personality Inventory (Neo PI) (3), Automatic Neuropsychological Assessment Metric - Isolated and Confined Environments 420 (ANAM-ICE) (3) and Center for Epidemiologic Studies
Depression Scale (CES-D) (3). Also noteworthy is the use of Sixteen Personality Factor Questionnaire (16PF), some Wechsler Adult Intelligence Scale (WAIS) subtests, and the "Selection of Antarctic Personnel battery" (SOAP) instrument from the Selection of Antarctic Personnel project, which was developed particularly to examine Antarctic expedition members (Grant et al., 2007; Palinkas, 2003). In addition, 20.4\% of the reviewed publications reported the employment of psychological assessment interviews. Overall, evaluation methods were combined for the proper assessment of psychological adaptation to that environment.

No study with Latin American crew members was identified in the databases searched.

\section{Discussion}

The aim of this review was to examine the publications of the 2000s, related to different variables in Antarctic Environmental Psychology in order to map trends and thus obtain a more realistic overview of the general interest shown in this research approach. The large amount of literature review studies evidences the permanent need for the synthesis and categorization of findings obtained in empirical studies. This is a relatively new and rather broad field of study and thus produces a large set of diffuse data related to the proportion of purely descriptive studies. However, there is an increasing interest in the comprehension of cause and effect mechanisms for the symptoms through experimental research. The predominance of austral winter investigation corroborates the intention of identifying and explaining the symptoms associated with larger social and physical deprivation, i.e., related to extreme environmental harshness.

Initially, it can be noticed that predominantly negative categories remain a central feature in polar psychology research, in consonance with research from previous decades (Wood, Hysong, Lugg \& Harm, 2000). However, during the 2000s, studies on symptom etiologies accounted for a significant percentile of publications. This reflects a concern with the influence that the environment may exert upon the development of such characteristics, namely those related to cognitive impairment symptoms. Exposure to extreme 
cold and isolation is often associated with reduced attention capacity, vigilance, reasoning, and memory, however, not all studies found this cognitive decline (John Paul et al., 2010). These findings may reveal tendencies in the research design centered on data generation toward promoting satisfactory individual performance as well as those of the work teams while the mission is being executed. In this research approach, the current focus is not only on how to deal with those problems that eventually emerge during the period of isolation and confinement, where the evacuation of a polar station might present rather difficult complexities, but also on preventing harm (Farrace et al., 2003; Palinkas et al., 2004b).

Palinkas and Suedfeld (2008) showed depression as one of the most common symptoms in Antarctic expeditions, followed by anxiety and irritability, thereby, even with few cases requiring clinical intervention, neglect of these factors could have serious consequences. The decrease in life and work satisfaction during a long period in Antarctica is frequently reported in the articles. This is mostly reported as temporary, i.e., as stages or a linear pattern for the adaptation to the environmental stressors (Palinkas \& Houseal, 2000). Nevertheless, environmental challenges may bring about stress, due to the overcoming of difficulties imposed upon polar teams (Norris, Paton \& Ayton, 2010; Weiss, Suedfeld, Steel \& Tanaka, 2000). After analyzing data referring to research reports, strong evidence supports the perspective that coping strategies can produce long-term salutogenic reactions in the expedition members' lives (Norris et al., 2010; Peri, Scarlata \& Barbarito, 2000; Palinkas \& Suedfeld, 2008). Accordingly, an increasing number of studies have been performed that are directed toward the understanding of the protection factors associated with well-being and professional performance under conditions of extreme adversity.

Psychosocial features may perform a significant role in the individual adaptation to extreme environments (Bhargava, Mukerji \& Sachdeva, 2000; Johnson, Boster $\&$ Palinkas, 2003). Research has revealed the key roles leadership and gender differences play in the functioning of the group and both factors are acknowledged as cohesion and adjustment facilitators within the team. In addition, openness in communication among members shows a central role within this psychosocial variable promoting better performance within the working teams (Atlis, Léon, Sandal \& Infante, 2004). Individual characteristics may provide good performance and successful adaptation. However, these data are controversial, indeed the multidimensionality shown by such variables within an environment of highly complex logistics has limited the research required for the determination of these patterns. The perception of this diversity presents a high value as it allows for the acknowledgment of the many possibilities of psychosocial adaptations for heterogenic groups submitted to an extreme environment.

Literature data indicate a wide variety of reactions in response to stressor conditions. The possibility of health-damaging reactions after a long-term stay in Antarctica is well-known. On the other hand, the studies on the positive aspects brought about by extreme expeditions have become a recurring differential in mission research and planning projects. Regardless of the nationality of the team, psychological selection, training, and support were approaches indicated as efficient predictors of well-being during the mission. It is important to highlight that the environment can be distressful even to highly-motivated subjects. Therefore, the exclusion of participants from the field assignment when they are considered unsuitable due to presenting a history of mental or hormonal disturbance is supported by a wide range of empirical findings.

A scientific consensus on some issues related to Antarctic Environmental Psychology is still missing. However, a number of consistent pieces of evidence supported by constant reviews of data generated from field research are significant for the composition of a general perspective on such findings. It is important to highlight that the logistical difficulties and the generally reduced number of research samples are inherent characteristics to Antarctic expeditions, which makes the accumulation of data in this area slow and sparse (Bishop, 2004; Palinkas et al., 2004c). Therefore, research protocols that prioritize methodologically standardized, systematic, cross-cultural, and multinational approaches are scientific advantages yet to be achieved.

It was noted that there are few standardized and validated psychological assessment instruments, which 
have been specifically elaborated for that particular, individual population. It is also important to highlight that the large diversity of instruments employed in the psychological assessment of the participants of research performed on that continent severely limits a more specific comparison of data. Nonetheless, some scientists have dealt with this deficiency striving to develop psychological assessment instruments capable of measuring the unique constructs related to Antarctica (Grant et al., 2007).

This approach is not only relevant to polar explorers. These results can contribute to the elaboration of public policies in favor of people who live in cities located at high latitudes, as well as provide indications on how subjects exposed to environmental stressors can react to them. Thus, these studies provide information about what can be done to promote satisfactory adaptation and reduce the psychological distress in these people.

\section{Final Considerations}

Antarctica's extreme conditions can provoke important cognitive and behavioral alterations in the members of polar expeditions. However, these alterations may result in a successful adaptation to the environment, i.e., salutogenic effects that might generate feelings of self-efficacy and a significant improvement in general health. Despite this, distress related to the expeditions' social and physical characteristics should not be overlooked, as the impact of stressors can impair individual and team performance and compromise crew members'health. Understanding and categorizing these effects is of major importance for the prevention of negative factors related to the psychosocial and neuropsychological adaptation brought about by unusual environmental conditions. Given the large amount of evidence gathered, it is suggested that the promotion of protective factors includes psychological support for team members; psychological training to deal with the environmental stressors; and, above all, a medical and psychological selection process in order to screen unfit candidates and to select the psychological characteristics that assist efficient adaptation.

These studies can also help with the understanding

422 of the underlying human behavior factor in other isolated and confined environment, such as space stations and submarines. Furthermore, polar expeditions can provide an analogy to the stressors of the urban populations in the face of environmental changes and catastrophic events. In order to better elucidate these questions, more research should be conducted to completely understand the mechanisms that are associated with the health and well-being promotion factors of individuals who live in extreme conditions. It should be noted that organic responses to the environment must not be evaluated out of their context. Therefore, due to the absence of studies with the Brazilian population, research is needed to address the psychological aspects of these expedition members in polar conditions, thereby seeking to generate support strategies considering the cultural traits of both the crew and the team.

\section{References}

Atlis, M. M., Leon, G. R., Sandal, G. M., \& Infante, M. G. (2004). Decision processes and interactions during a two-women traverse of Antarctica. Environment and Behavior, 36(3), 402-423.

Bhargava, R., Mukerji, S., \& Sachdeva, U. (2000). Psychological impact of the Antarctic winter on indian expeditioners. Environment and Behavior, 32(1), 111-127.

Bishop, S. L. (2004). Evaluating teams in extreme environments: From issues to answers. Aviation Space and Environmental Medicine, 75(7), C14-C21.

Bradbury, J. (2002). Utter isolation in a cold climate: The Antarctic challenge. The Lancet, 359(9312), 1130.

Daher, E., \& Brito, T. A. S. (2007). O Brasil e o meio ambiente antártico. Brasília: MEC.

Décamps, G., \& Rosnet, E. (2005). A longitudinal assessment of psychological adaptation during a winter-over in Antarctic. Environment and Behavior, 37(3), 418-435.

Farrace, S., Ferrara, M., De Angelis, C., Trezza, R., Cenni, P., Peri, A., et al. (2003). Reduced sympathetic outflow and adrenal secretory activity during a 40-day stay in the Antarctic. International Journal of Psychophysiology, 49(1), 17-27.

Grant, I., Eriksen, H. R., Marquis, P., Orre, I. J., Palinkas, L. A., Suedfeld, P., et al. (2007). Psychological selection of Antarctic personnel: The "SOAP" instrument. Aviation Space and Environmental Medicine, 78(8), 793-800.

John Paul, F. U., Mandal, M. K., Ramachandran, K., \& Panwar, M. R. (2010). Cognitive performance during long-term residence in a polar environment. Journal of Environmental Psychology, 30(1), 129-132.

Johnson, J. C., Boster, J. S., \& Palinkas, L. A. (2003). Social roles and the evolution of networks in extreme and isolated environments. Journal of Mathematical Sociology, 27(2-3), 89-121. 
Law, P. (1960). Personality problems in Antarctica. The Medical Journal of Australia, 47(1), 273-282.

Lugg, D. J. (2005). Behavioral health in Antarctica: Implications for long-duration space missions. Aviation Space and Environmental Medicine, 76(6), B74-B77.

Lugg, D., \& Shepanek, M. (1999). Space analogue studies in Antarctica. Acta Astronautica, 44(7), 693-699.

Mullin, C. S. (1960). Some psychological aspects of isolated Antarctic living. The American Journal of Psychiatry, 117(4), 323-325.

Nelson, P. D. (1963). Human adaptation to Antarctic station life. Public Health Papers, 18, 138-145.

Noakes, T. D. (2006). The limits of endurance exercise. Basic Research in Cardiology, 101(5), 408-417.

Norris, K., Paton, D., \& Ayton, J. (2010). Future directions in Antarctic psychology research. Antarctic Science, 22(4), 335-342.

Palinkas, L. A. (1986). Health and performance of Antarctic winter-over personnel: A follow-up study. Aviation Space and Environmental Medicine, 57(10), 954-959.

Palinkas, L. A. (1991). Effects of physical and social environment on the health and well-being of Antarctic winter-over personnel. Environment \& Behavior, 23(6), 782-799.

Palinkas, L. A. (1992). Going to extremes: The cultural context of stress, illness and coping in Antarctica. Social Science and Medicine, 35(5), 651-664.

Palinkas, L. A. (2003). The psychology of isolated and confined environments: Understanding human behavior in Antarctica. American Psychologist, 58(5), 353-363.

Palinkas, L. A., Cravalho, M., \& Browner, D. (1995). Seasonal variation of depressive symptoms in Antarctica. Acta Psychiatrica Scandinavica, 91 (6), 423-429.

Palinkas, L. A., \& Houseal, M. (2000). Stages of change in mood and behavior during a winter in Antarctica. Environment and Behavior, 32(1), 128-141.

Palinkas, L. A., Glogower, F., Dembert, M., Hansen, K., \& Smullen, R. (2004a). Incidence of psychiatric disorders after extended residence in Antarctica. International Journal of Circumpolar Health, 63(2), 157-168.

Palinkas, L. A., Houseal, M., \& Rosenthal, N. (1996). Subsyndromal seasonal affective disorder in Antarctic. Journal of Nervous and Mental Disease, 184(9), 530-534.

Palinkas, L. A., Johnson, J. C., \& Boster, J. S. (2004b). Social support and depressed mood in isolated and confined environments. Acta Astronautica, 54(9), 639-647.

Palinkas, L. A., Johnson, J. C., Boster, J. S., Rakusa-Suszczewski, S., Klopov, V. P., Xue, Q. F., et al. (2004c). Cross-cultural differences in psychosocial adaptation to isolated and confined environments. Aviation Space and Environmental Medicine, 75(11), 973-980.

Palinkas, L. A., Reed, H. L., Reedy, K. R., Do, N. V., Case, H. S., \& Finney, N. S. (2001). Circannual pattern of hypothalamicpituitary-thyroid (HPT) function and mood during extended Antarctic residence. Psychoneuroendocrinology, 26(4), 421-431.

Palinkas, L. A., \& Suedfeld, P. (2008). Psychological effects of polar expeditions. The Lancet, 371(9607), 153-163.
Palmai, G. (1963). Psychological observations on an isolated group in Antarctica. British Journal of Psychiatry, 131, 651-654.

Peri, A., Scarlata, C., \& Barbarito, M. (2000). Preliminary studies on the psychological adjustment in the italian Antarctic summer campaigns. Environment and Behavior, 32(1), 72-83.

Reed, H. L., Reedy, K. R., Palinkas, L. A., Do, N. V., Finney, N. S., Case, H. S., et al. (2001). Impairment in cognitive and exercise performance during prolonged antarctic residence: Effect of thyroxine supplementation the polar triiodothyronine syndrome.JournalofClinical Endocrinology and Metabolism, 86(1), 110-116.

Rosnet, E., Jurion, S., Cazes, G., \& Bachelard, C. (2004). Mixed-gender groups: Coping strategies and factors of psychological adaptation in a polar environment. Aviation Space and Environmental Medicine, 75(7), C10-C13.

Rosnet, E., Le Scanff, C., \& Sagal, M. (2000). How self-image and personality influence performance in an isolated environment. Environment and Behavior, 32(1), 18-31.

Sandal, G. M., Leon, G., \& Palinkas, L. (2006). Human challenges in polar and space environments. Environmental Science and Biotechnology, 5(2-3), 281-296.

Schmidt, L., Wood, J., \& Lugg, D. J. (2005). Gender differences in leader and follower perceptions of social support in Antarctica. Acta Astronautica, 56(9-12), 923-931.

Souza, J. E. B. (2008). Brasil na Antártica 25 anos de história. São Carlos: Vento Verde.

Steel, G. D. (2005). Whole lot of parts: Stress in extreme environments. Aviation Space and Environmental Medicine, 76(6), B67-B73.

Suedfeld, P. (1998). What can abnormal environments tell us about normal people? Polar stations as natural psychology laboratories. Journal of Environmental Psychology, 18(1), 95-102.

Suedfeld, P., \& Steel, G. D. (2000). The environmental psychology of capsule habitats. Annual Review of Psychology, 51, 227-253.

Suedfeld, P., \&Weiss, K. (2000). Antarctica: Natural laboratory and space analogue for psychological research. Environment and Behavior, 32(1), 7-17.

Tafforin, C. (2002). Ethological observations on a small group of wintering members at dumont d'urville station (terre Adeilie). Antarctic Science, 14(4), 310-318.

Weiss, K., Suedfeld, P., Steel, G. D., \& Tanaka, M. (2000). Psychological adjustment during three Japanese Antarctic research expeditions. Environment and Behavior, 32(1), $142-156$.

Wood, J. A., Hysong, S. J., Lugg, D. J., \& Harm, D. L. (2000). Is it really so bad? A comparison of positive and negative experiences in Antarctic winter stations. Environment and Behavior, 32(1), 84-110.

Wood, J., Lugg, D. J., Hysong, S. J., \& Harm, D. L. (1999). Psychological changes in hundred-day remote Antarctic field groups. Environment and Behavior, 31(3), 299-337.

Received on: 27/7/2011

Approved on: 24/5/2012 